\title{
Introduction: Indications for invasive mediastinal staging for non-small cell lung cancer
}

\author{
Bryan M. Burt, MD
}

\footnotetext{
From the Division of General Thoracic Surgery, Michael E. DeBakey Department of Surgery, Baylor College of Medicine, Houston, Tex.

Disclosures: Author has nothing to disclose with regard to commercial support.

Received for publication Nov 9, 2018; revisions received Nov 9, 2018; accepted for publication Nov 12, 2018; available ahead of print Dec 19, 2018

Address for reprints: Bryan M. Burt, MD, Division of General Thoracic Surgery, Department of Surgery, Baylor College of Medicine, One Baylor Plaza, MS: BCM 390, Houston, TX 77030 (E-mail: bryan.burt@bcm.edu). J Thorac Cardiovasc Surg 2019;157:1248

$0022-5223 / \$ 36.00$

Copyright (c) 2018 by The American Association for Thoracic Surgery

https://doi.org/10.1016/j.jtcvs.2018.11.037
}

Clinical stage directs the most effective treatment for patients with cancer. Whereas it therefore may seem obvious to state the importance of accurate clinical staging in this non-small cell lung cancer (NSCLC), the nonadherence to staging guidelines now published in a number of studies is alarming. In NSCLC, invasive nodal sampling is a vital component of clinical staging. The presence of nodal metastases in mediastinum indicates stage III disease in patients with NSCLC, IIIA when on the ipsilateral side relative to the primary tumor, and IIIB when on the contralateral side. Stage IIIA disease secondary to mediastinal nodal disease is a heterogenous disease with presentations ranging from radiographically negative microscopic disease in a single node (occult N2 disease) to bulky, multi-station nodal disease. Where lobectomy with nodal dissection has a role in the treatment of some patients with stage IIIA NSCLC, it is performed in the setting of multimodal therapy most often including neoadjuvant chemotherapy or chemoradiation, and the balance evidence suggests that best outcomes are achieved in the subcategory of patients with single station, nonbulky nodal disease. Thus, the ramifications of accurate pretreatment staging in NSCLC are vast. At one extreme, invasive mediastinal staging may reveal or confirm extensive mediastinal disease and spare futile surgery. Alternatively, a patient with a radiographically negative mediastinum may be upstaged by invasive nodal staging, facilitating a comprehensive multimodality care plan more likely to

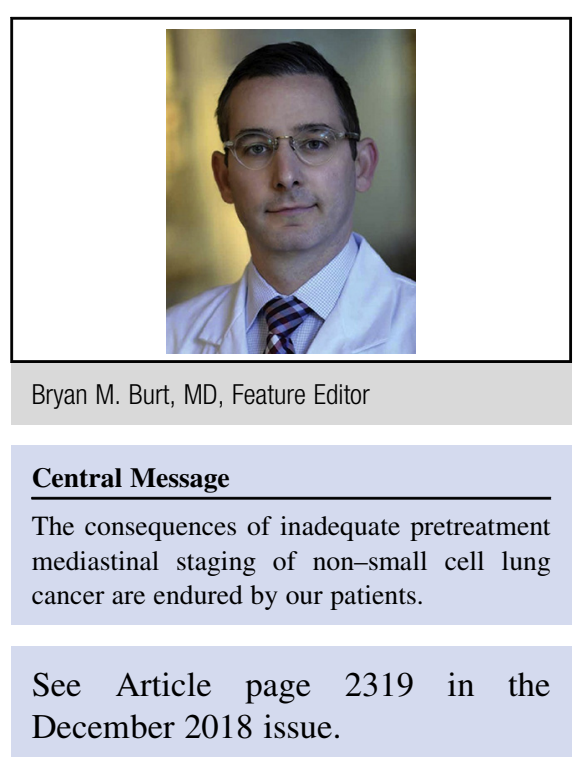

result in cure. Published guidelines on the use of invasive mediastinal staging are available from 3 organizations including the American College of Chest Physicians (ACCP), the European Society of Thoracic Surgeons (ESTS), and the National Comprehensive Cancer Network (NCCN). The recommendations from these groups are generally similar and are based upon the likelihood of mediastinal nodal metastases among patients with different tumor characteristics including size and centrality. The Feature Expert Opinion by Lin and Fernandez ${ }^{1}$ is a succinct and clear summary of evidence-based indications for invasive mediastinal staging, is anticipated to be one of the most downloaded articles from The Journal, and, in itself, may positively influence practice patterns in the care of patients with NSCLC.

\section{Reference}

1. Lin J, Fernandez F. Indications for invasive mediastinal staging for non-small cell lung cancer. J Thorac Cardiovasc Surg. 2018;156:2319-24. 